\title{
5 Research Square

\section{A comparative study of partial-threaded cannulated screws and double-threaded cannulated screws in the fixation of vertical femoral neck fractures}

\section{Yuelei Zhang}

Department of Orthopaedics, The First Affiliated Hospital of Anhui Medical University

\section{Gang Wang}

Department of orthopaedics, the First Affiliated Hospital of Anhui Medical University

Wei Zhang ( $\nabla$ orthozhang5233@163.com )

Department of Orthopedic Surgery, Shanghai Jiao Tong University Affiliated Sixth People's Hospital

\section{Research article}

Keywords: vertical femoral neck fractures, double-threaded cannulated screws, fixation failure, nonunion

Posted Date: January 13th, 2020

DOl: https://doi.org/10.21203/rs.2.20712/v1

License: (c) (i) This work is licensed under a Creative Commons Attribution 4.0 International License.

Read Full License 


\section{Abstract}

Background This study purposed to compare the partial- threaded cannulated screws (PTCS) and the double-threaded cannulated screws (DTCS) in vertical shear femoral neck fractures both clinically and biomechanically.

Methods Clinally, the radiographs of 81 patients with Pauwels $\otimes$ femoral neck fractures, including 54 fractures fixed with PTCS and 27 fractures fixed with DTCS were analyzed. Complications consist of fixation failure (nail withdrawal, obvious fracture displacement, varus deformity or femoral neck shortening), bony nonunion and avascular necrosis (AVN) were determined. Biomechanically, twenty femur synthetic bones were equally divided and made to a vertical femoral neck fracture model, then fixed with three parallel PTCSs or DTCSs respectively. All specimens were tested for axial stiffness and a maximum load to failure with a loading rate of $2 \mathrm{~mm} / \mathrm{min}$.

Results Clinically , 22 fractures in the PTCS group experienced fixation failure, including 19 nail withdrawal, 18 femoral neck shortening, 14 varus deformity and 8 obvious fracture displacement; while only 5 fractures showed up with fixation failure in the DTCS group, including 3 nail withdrawal, 4 femoral neck shortening, 4 varus deformity and 1 obvious fracture displacement. Additionally, 11 fractures in the PTCS group had nonunion while only 3 in the DTCS group and 9 fractures with AVN in the PTCS group while only 2 in the DTCS group. Biomechanically, The axial stiffness of DTCS was $152.89 \pm 22.74 \mathrm{~N} / \mathrm{mm}$, greater than PTCS (134.68 \pm 26.61$)$, moreover, the failure load in DTCS was significantly greater than PTCS $(1148.11 \pm 124.80$ vs $795.88 \pm 162.50)$.

Conclusion DTCS may exert more advantages than PTCS for vertical femoral neck fractures, including stronger fixation stability, lower rate of fixation failure and nonunion.

\section{Background}

Femoral neck fracture in young adults is usually the result of high energy,salvage of the femoral head with anatomic reduction and stable fixation is preferred [1,2]. Cannulated screws have become the most common fixation device due to its liner dynamic compression during weight bearing, less invasive surgery, less blood loss, and a shorter hospital stay [3]. However, for vertical shear femoral neck fractures, high rates of complications including displacement, screw withdrawal, nonunion and femoral head avascular necrosis have been reported by many authors when fixed with ordinary cannulated screws $[4,5]$.

The double-threaded cannulated screws (DTCS) have been used for fractures of many sites such as scaphoid [6], medial malleolus[7] and olecranon[8] with favorable clinical results reported in literatures, while rare outcomes of DTCS with the femoral neck fracture were reported, which functions through initial linear compression and final locking with proximal lateral femoral cortex. The purpose of this study is to compare the clinical and mechanical outcomes of the two types of cannulated screws including the partial-threaded cannulated screws (PTCS) and the DTCS when used in vertical shear femoral neck fractures. 


\section{Materials And Methods Patients and methods}

This research has been approved by the IRB of the authors' affiliated institutions, the office approved that verbal consent obtained by telephone was required because this study is retrospective and all the radiographs and data needed in this study were recorded in the case system of the hospital. From January 2016 to December 2017, 417 femoral neck fractures treated with internal fixation were retrospectively studied. The exclusion criteria were as follows: 1 . Fractures treated with other internal fixation constructs rather than three parallel cannulated screws, including four cannulated screws with a cross screw, sliding hip screw plus with an additional anti-rotation screw. 2. Femoral head fracture together with other ipsilateral or contralateral lower limb fracture. 3. Fractures with ORIF. 4. Patients without adequate reduction postoperatively. 4. Pathological fractures. 5. Femoral neck fractures with Pauwels angle less than 50 degrees in standard anteroposterior pelvic radiographs before or after operation. 6. Fractures with follow-up period shorter than 9 months. Adequate reduction was considered when a femoral neck angle was $<10^{\circ}$ varus or $<15^{\circ}$ valgus and the displacement between the fracture fragments was less than $<3 \mathrm{~mm}$ on AP and lateral radiographs, compared to the contralateral hip on an anteroposterior (AP) pelvis radiograph [9]. The patients and/or their families were informed and approved that data from the cases would be submitted for publication.

Finally, 81 patients with Pauwels $\otimes$ vertical femoral neck fractures were included in this study, including 54 fractures fixed with PTCS $(7.3 \mathrm{~mm})$ and 27 fractures fixed with DTCS $(7.3 \mathrm{~mm})$ (Fig. 1). All patients followed the similar postoperative protocol as follows: no weight bearing of the affected limb within 3 months, partial weight bearing after bone union and totally weight bearing until 6 months postoperatively.

\section{Radiographic analysis}

Anteroposterior and the lateral radiographs were taken at 6 weeks, 3 months, 6 months, 9 months, 12 months after the surgery, and any time when pain appeared at the injured hip. Fixation failure was defined as screw withdrawal, obvious fracture displacement $(>5 \mathrm{~mm})$, varus deformity $\left(>10^{\circ}\right)$ or femoral neck shortening ( $>10 \mathrm{~mm}$ vertically) compared with preliminary fixation[10-12]. Bone nonunion was defined as lack of any healing on plain or CT radiographs within 9 months. Avascular necrosis was defined as the appearance of subchondral sclerosis or the presence of segmental collapse[12]. All radiographs were collected and analyzed by the authors with a consensus.

\section{Specimen preparation}

Twenty femur synthetic bones with the same shape were equally divided into two groups with 10 treated with PTCS and another 10 with DTCS. All specimens were predrilled under C-arm fluoroscopic guidance prior to osteotomy to facilitate an anatomic reduction and ideal implant positioning. The vertical fracture model was osteotomized with an oscillating saw at an $80^{\circ}$ angle to the horizontal line and then repaired 
with three parallel PTCS or DTCS with the same configuration. Distally,all the models were osteotomized horizontally at the inferior segment with the same height from the apex of greater trochanter.

\section{Biomechanical analysis}

The biomechanical analysis was done using an Instron test system (Instron, Norwood, MA, USA).

Proximally, two magnets were placed respectively on the femoral head and proximal femur to record the displacement of the femoral head with an axial loading. Distally, the femur was fixed to the base of a mechanical tester with dental powder at a shaft adduction angle of $7 \circ$ to simulate normal walking. All tests were conducted with an axial compressive loading which was performed with a loading rate of $2 \mathrm{~mm} / \mathrm{min}$, the maximum load for failure was defined by the destructive construct failure followed by a marked decrease in the applied load value[13, 14] (Fig. 2).

\section{Statistical analysis}

The data including the gender and hip affected was compared using chi-square test, all measurement data including the age, Pauwels angle, follow-up period, the axial failure load and stiffness between the two groups were expressed with mean \pm standard deviation, and compared using Independent sample $t$ test, The statistical analysis was performed with SPSS and significant difference was considered when $\mathrm{P}$ $<0.05$.

\section{Results}

At the beginning, we performed the retrospective study, the mean age of patients in the PTCS group was $49.1 \pm 12.5$ years with no statistical difference with the patients in the DTCS group ( $45.8 \pm 14.2)$. There were 30 (55.6\%) males included in the PTCS cohort and 17 males (63\%) in the DTCS cohort, 31 patients (57.4\%) in the PTCS group had the right hip affected and 16 (59.3\%) in the DTCS group. The mean follow-up period of patients treated with PTCS was $18.15 \pm 6.45$ months, which is similar with that in the DTCS group (18.48 \pm 3.47 ) (Table 1). 
Table 1

Patient demographics and clinical characteristics

\begin{tabular}{|llll|}
\hline & PTCS & DTCS & p \\
\hline number & 54 & 27 & - \\
\hline Age(years old) & $49.1 \pm 12.5$ & $45.8 \pm 14.2$ & $0.372^{\mathrm{a}}$ \\
\hline Sex (M/F) & $30 / 24$ & $17 / 10$ & $0.524^{\mathrm{b}}$ \\
\hline Hip (R/L) & $31 / 23$ & $16 / 11$ & $0.874^{\mathrm{b}}$ \\
\hline Follow-up period(month) & $18.15 \pm 6.45$ & $18.48 \pm 3.47$ & $0.803^{\text {a }}$ \\
\hline Pauwels angle $\left({ }^{\circ}\right)$ & $58.64 \pm 5.23$ & $57.54 \pm 5.62$ & $0.807^{\text {a }}$ \\
\hline $\begin{array}{l}\text { Data are expressed as mean } \pm \text { standard deviation unless stated otherwise; }{ }^{\text {a }} \text { independent sample } \mathrm{t} \\
\text { test; }{ }^{\mathrm{b}} \text { chi-square test; }\end{array}$ & & \\
\hline
\end{tabular}

For these fractures, no obvious difference was found between the Pauwels angle in the two groups (58.64 \pm 5.23 in the PTCS group vs $57.54 \pm 5.62$ in the DTCS group), which were measured on the standard antero-posterior pelvic $X$ ray before or after the surgery (Table 1). However, distinctly different radiographic outcomes were observed between them. Twenty-two $(40.74 \%)$ fractures in the PTCS group experienced fixation failure, including 19 (35.19\%) screw withdrawal, 18 (33.33\%) femoral neck shortening (>10 mm vertically), $14(25.93 \%)$ varus deformity $\left(>10^{\circ}\right)$ and $8(14.81 \%)$ obvious fracture displacement $(>5 \mathrm{~mm})$, since different types of fixation failure always appears together; while $5(18.52 \%)$ fractures showed up with fixation failure in the DTCS group, including $3(11.11 \%)$ screw withdrawal, 4 (14.81\%) femoral neck shortening, $4(14.81 \%)$ varus deformity $\left(>10^{\circ}\right)$ and $1(3.70 \%)$ obvious fracture displacement (>5 mm) (Fig. 3). Additionally, 11(20.37\%) fractures in the PTCS group had nonunion but only $3(11.11 \%)$ fractures in the DTCS group (Fig. 4). Furthermore, we observed 9 (16.67\%) AVN in the PTCS group and only 2 (7.41\%) AVN in the DTCS group (Table 2). 
Table 2

QRadiographic analysis of fractures fixed with PTCS

and DTCS

\begin{tabular}{|lll|}
\hline & PTCS (\%) & DTCS (\%) \\
\hline Number & 54 & 27 \\
\hline Nail-withdrawal & $19(35.19)$ & $3(11.11)$ \\
\hline Femoral neck shortening & $18(33.33)$ & $4(14.81)$ \\
\hline Varus deformity & $14(25.93)$ & $4(14.81)$ \\
\hline Fracture Displacement & $8(14.81)$ & $1(3.7)$ \\
\hline Nonunion & $11(20.37)$ & $3(11.11)$ \\
\hline ONFH & $9(16.67)$ & $2(7.41)$ \\
\hline
\end{tabular}

The axial stiffness of DTCS was $152.89 \pm 22.74 \mathrm{~N} / \mathrm{mm}$, which was greater than PTCS $(134.68 \pm 26.61)$, although not significantly. Moreover, the axial compression yielding fixation failure in DTCS was significantly greater than PTCS (1148.11 \pm 124.80 vs $795.88 \pm 162.50)$, indicating stronger biomechanical stability of DTCS than PTCS (Fig. 5).

\section{Discussion}

High rates of complications with Pauwels $₫$ vertical femoral neck fractures has been reported by many authors, especially for fractures fixed with PTCS. In this study, we compared the fixation outcomes of PTCS and DTCS both clinically and biomechanically, our results showed that DTCS had less fixation failure rates and stronger stability than PTCS, indicating DTCS was a promising fixation constructs for vertical femoral neck fractures.

For more vertical femoral neck fractures that are axial and rotationally unstable, strong shear forces across the hip frequently led to fixation failure, with overall complication rates ranging from $20-86 \%[9$, $15,16]$. No standard internal fixation has been clinically proven to be superior for vertical fractures, although the addition of a cross screw or combination of a sliding hip screw and an additional antirotation screw has been recommended[17], but higher nonunion and AVN rates was reported by Parker [18]. In addition, a medial buttress plate was proposed to augment the fixation of ordinary cannulated screws, which still need longer follow-up and larger sample size[3].

DTCS exerts both linear compression and angle stability with proximal cortex locking. At the beginning of fixation, the near thread supplies the compression between fractures by screwing in, and finally, the proximal thread makes the femoral head and the screws a whole. This locking effect provides enough support on the lateral femoral cortex to significantly lessen the rate of varus deformity compared to PTCS 
[19], moreover, the occurrence of screw withdrawal was also reduced in DTCS as observed in our retrospective study.

Fracture union depends on the stability between fractures, for vertical femoral neck fractures fixed with PTCS, the strong shear force leads to displacement and finally nonunion due to slide of screws, while for DTCS, fracture displacement and nonunion were significantly reduced as a result of lateral cortex locking, even for femoral neck fractures with posterior neck comminution[20], the angle stability also decreases the fracture displacement and facilitates the union of fractures. Our mechanical analysis further illustrated stronger fixation stability of DTCS than PTCS.

$\mathrm{AVN}$ is one of the most common complications of femoral neck fractures due to the damage of the special blood supply of the femoral head, the overall occurrence of AVN is as high as $20-30 \%$ after fractures[21], although a lower rate of AVN of DTCS than PTCS was observed in our study, but symptomatic AVN may appear as late as 6 years post injury and $29 \%$ of patients with AVN showed no significant symptom [20]. Therefore, due to the limited and non-scheduled follow-up of this study, the finding means little.

Several limitations of this study including the retrospective nature, the small number of patients available for radiographic follow-up and synthetic bones rather than fresh-frozen human cadaveric specimens were acknowledged. Despite that, we clearly proved the advantages of DTCS for vertical femoral neck fractures, of course, a larger scale study is still needed to strengthen these conclusions.

\section{Conclusion}

In summary, DTCS may exert more advantages than PTCS, especially for Pauwels $\otimes$ vertical femoral neck fractures, including stronger fixation stability, lower rates of fixation failures and nonunion.

\section{Abbreviations}

DTCS: double-threaded cannulated screws. PTCS: partial- threaded cannulated screws. AVN: avascular necrosis.

\section{Declarations}

\section{Ethics approval and consent to participate}

This research has been approved by the IRB of the authors' affiliated institutions, the office approved that verbal consent obtained by telephone was required because this study is retrospective and all the radiographs and data needed in this study were recorded in the case system of the hospital.

\section{Consent for publication}


The patients and/or their families were informed and approved that data from the cases would be submitted for publication.

\section{Availability of data and materials}

The datasets used and/or analyzed during the current study are available from the corresponding author on reasonable request.

\section{Competing interests}

The authors declare that they have no competing interests.

\section{Funding}

This study was funded by the National Natural Science Foundation of China (NO. 81702134).

\section{Authors' contributions}

YLZ collected and analyzed the data, searched the literatures and drafted the manuscript. GW and WZ participated in study design, collected and analyzed the data, revised the manuscript, and acted as the cocorresponding authors. All authors read and approved the final manuscript.

\section{Acknowledgments}

We thank the staff in the biomechanics laboratory of the Sixth Peoples' Hospital for their help in the biological tests.

\section{References}

1. Duckworth AD, Bennet SJ, Aderinto $J$ and Keating JF. Fixation of intracapsular fractures of the femoral neck in young patients: risk factors for failure. J Bone Joint Surg Br 2011; 93:811-816.

2. Sprague S, Slobogean GP, Scott T, Chahal M and Bhandari M. Young femoral neck fractures: are we measuring outcomes that matter? Injury 2015; 46:507-514.

3. Ye Y, Ke C, Kewei T, Wuyin L, Mauffrey $C$ and Hak DJ. Medial buttress plate augmentation of cannulated screw fixation in vertically unstable femoral neck fractures: Surgical technique and Preliminary results. Injury 2017; S0020138317305302.

4. Liporace F, Gaines R, Collinge $C$ and Haidukewych GJ. Results of internal fixation of Pauwels type-3 vertical femoral neck fractures. J Bone Joint Surg Am 2008; 90:1654-1659.

5. Zhang YL, Chen S, Ai ZS, Gao YS, Mei J and Zhang CQ. Osteonecrosis of the femoral head, nonunion and potential risk factors in Pauwels grade-3 femoral neck fractures: A retrospective cohort study. Medicine 2016; 95:e3706.

6. Neshkova IS, Jakubietz RG, Kuk D, Jakubietz MG, Meffert RH and Schmidt K. Percutaneous screw fixation of non- or minimally displaced scaphoid fractures. Oper Orthop Traumatol 2015; 27: 448- 
454.

7. Fujioka $\mathrm{H}$, Tsunemi $\mathrm{K}$, Takagi $\mathrm{Y}$ and Tanaka J. Treatment of stress fracture of the olecranon in throwing athletes with internal fixation through a small incision. Sports Med Arthrosc Rehabil Ther Technol 2012; 4: 49.

8. Kanto R, Fukunishi S, Morooka T, Seino D, Takashima T, Yoshiya S, et al. Double threaded screw fixation for bilateral stress fracture of the medial malleolus. Case Rep Orthop 2014; 2014:729035.

9. Enocson A and Lapidus LJ. The vertical hip fracture - a treatment challenge. A cohort study with an up to 9 year follow-up of 137 consecutive hips treated with sliding hip screw and antirotation screw. BMC Musculoskelet Disord 2012; 13: 171.

10. Zlowodzki M, Brink O, Switzer J, Wingerter S, Woodall J, Jr., et al. The effect of shortening and varus collapse of the femoral neck on function after fixation of intracapsular fracture of the hip: a multicentre cohort study. J Bone Joint Surg Br 2008; 90:1487-1494.

11. Huang TW, Hsu WH, Peng KT and Lee CY. Effect of integrity of the posterior cortex in displaced femoral neck fractures on outcome after surgical fixation in young adults. Injury 2011; 42: 217-222.

12. Upadhyay A, Jain P, Mishra P, Maini L, Gautum VK and Dhaon BK. Delayed internal fixation of fractures of the neck of the femur in young adults. A prospective, randomised study comparing closed and open reduction. J Bone Joint Surg Br 2004; 86: 1035-1040.

13. Nowotarski PJ, Ervin B, Weatherby B, Pettit J, Goulet R and Norris B. Biomechanical analysis of a novel femoral neck locking plate for treatment of vertical shear Pauwel's type $\mathrm{C}$ femoral neck fractures. Injury 2012; 43: 802-806.

14. Rupprecht M, Grossterlinden L, Ruecker AH, de Oliveira AN, Sellenschloh K, Nuchtern J, et al. A comparative biomechanical analysis of fixation devices for unstable femoral neck fractures: the Intertan versus cannulated screws or a dynamic hip screw. J Trauma 2011; 71:625-634.

15. Collinge $\mathrm{CA}$, Mir $\mathrm{H}$ and Reddix R. Fracture morphology of high shear angle "vertical" femoral neck fractures in young adult patients. J Orthop Trauma 2014; 28: 270-275.

16. Freitas A, Maciel RA, Lima Rde A, Souto DR and Ferrer Mde A. Mechanical analysis of femoral neck fracture fixation with dynamic condylar screw in synthetic bone. Acta Ortop Bras 2014; 22: 264-268.

17. Guimar?Es JOAM, Rocha LR, Noronha Rocha TH, Bonfim DC, da Costa RS, dos Santos Cavalcanti A, et al. Vertical femoral neck fractures in young adults: a closed fixation strategy using a transverse cancellous lag screw. Injury, 2017, 48:S10-S16.

18. Parker MJ, Porter KM, Eastwood DM, Schembi Wismayer M and Bernard AA. Intracapsular fractures of the neck of femur. Parallel or crossed garden screws? J Bone Joint Surg Br 1991; 73: 826-827.

19. Parker M, Cawley S and Palial V. Internal fixation of intracapsular fractures of the hip using a dynamic locking plate: Two-year follow-up of 320 patients. Bone Joint J 2013; 95-b: 1402-1405.

20. Davidovitch RI, Jordan CJ, Egol KA and Vrahas MS. Challenges in the treatment of femoral neck fractures in the nonelderly adult. J Trauma 2010; 68: 236-242. 
21. Liu Y, Li M, Zhang M, Sun K, Wang H, Yuan X, et al. Femoral neck fractures: prognosis based on a new classification after superselective angiography. J Orthop Sci 2013; 18: 443-450.

\section{Figures}
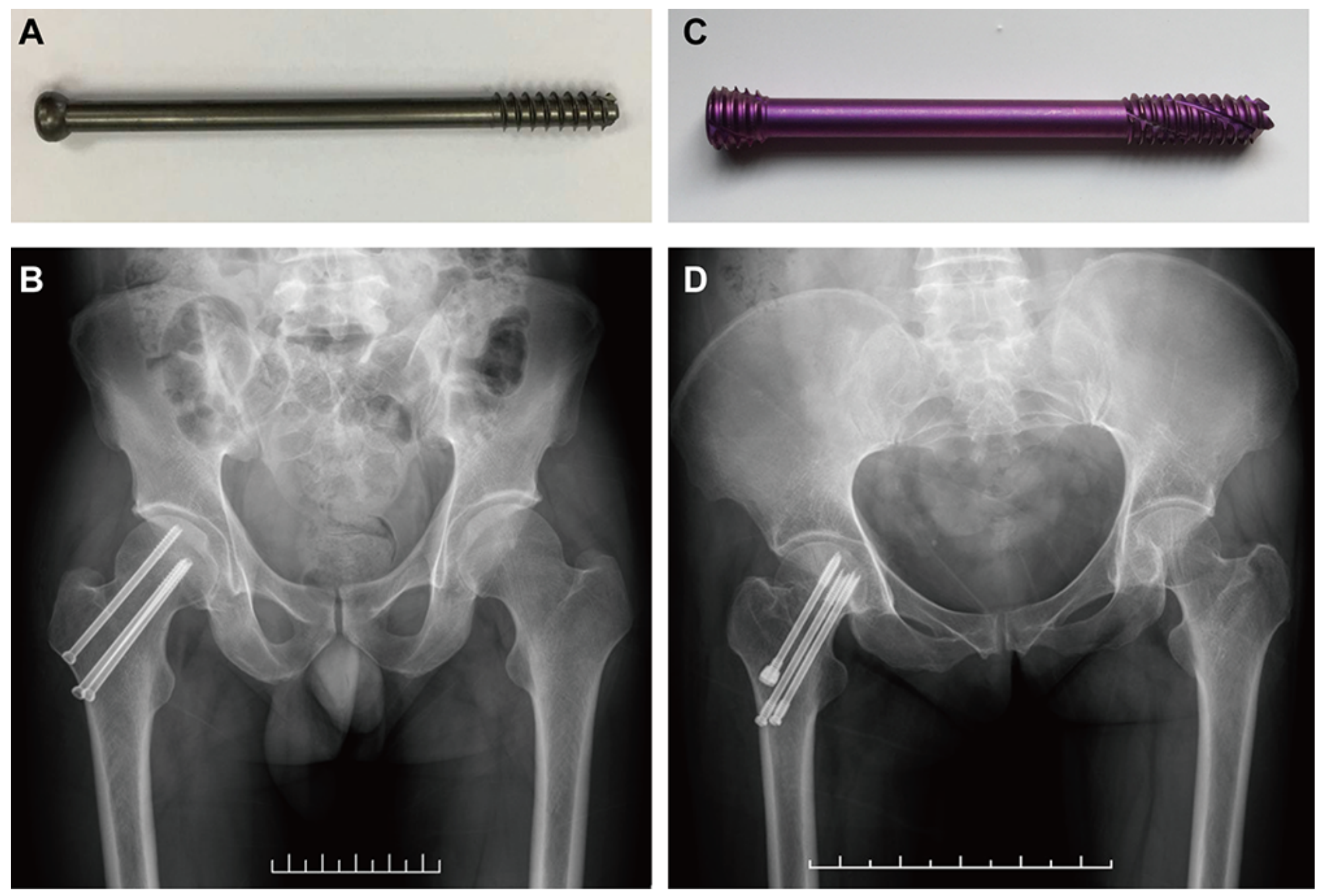

\section{Figure 1}

Application of PTCS (partial-threaded cannulated screws) and DTCS (double-threaded cannulated screws) in femoral neck fractures. A, B. The partial- threaded cannulated screws. C, D. The doublethreaded cannulated screws 

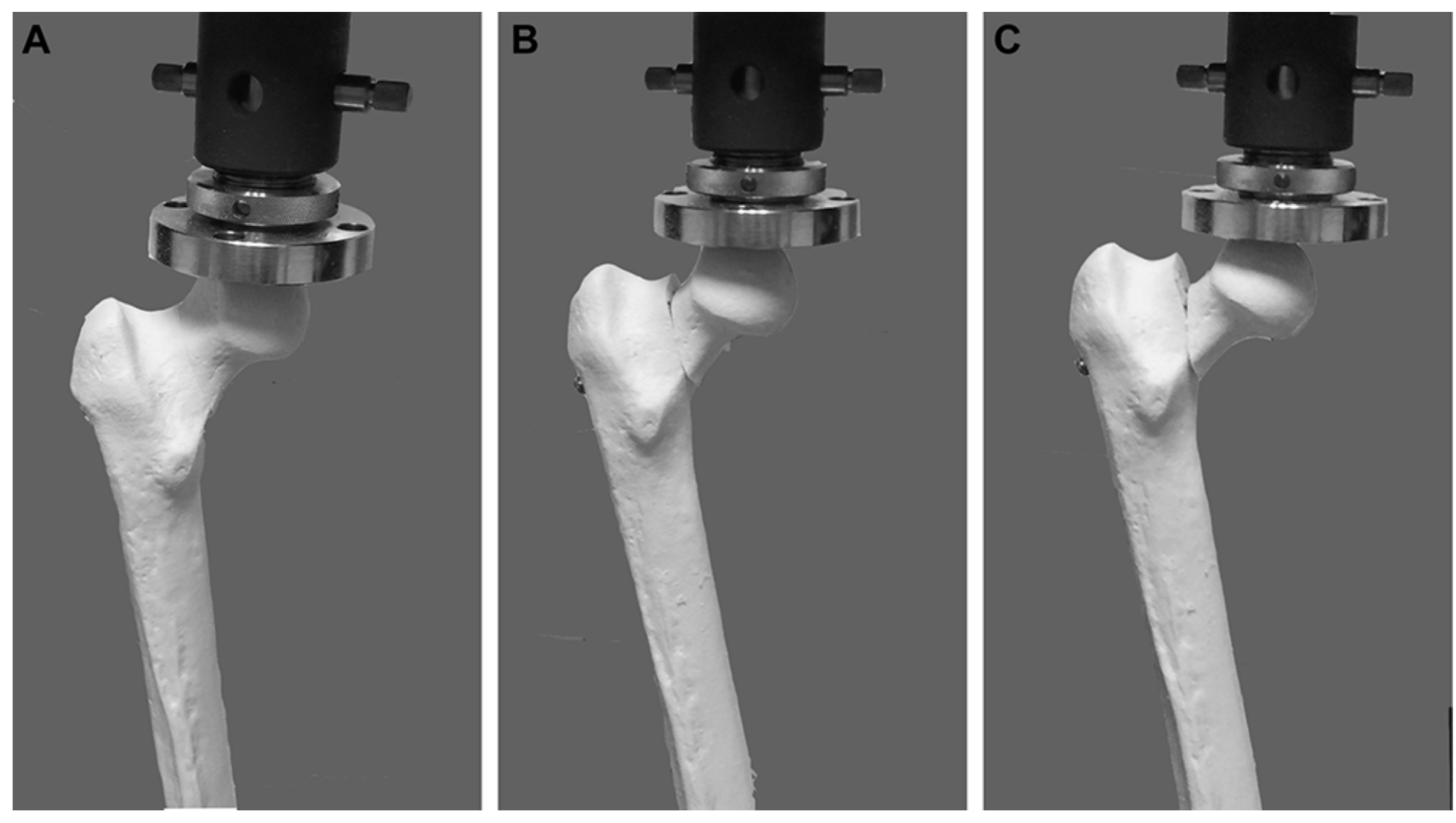

\section{Figure 2}

Biomechanical process of a femur synthetic bone model fixed with cannulated screws. 

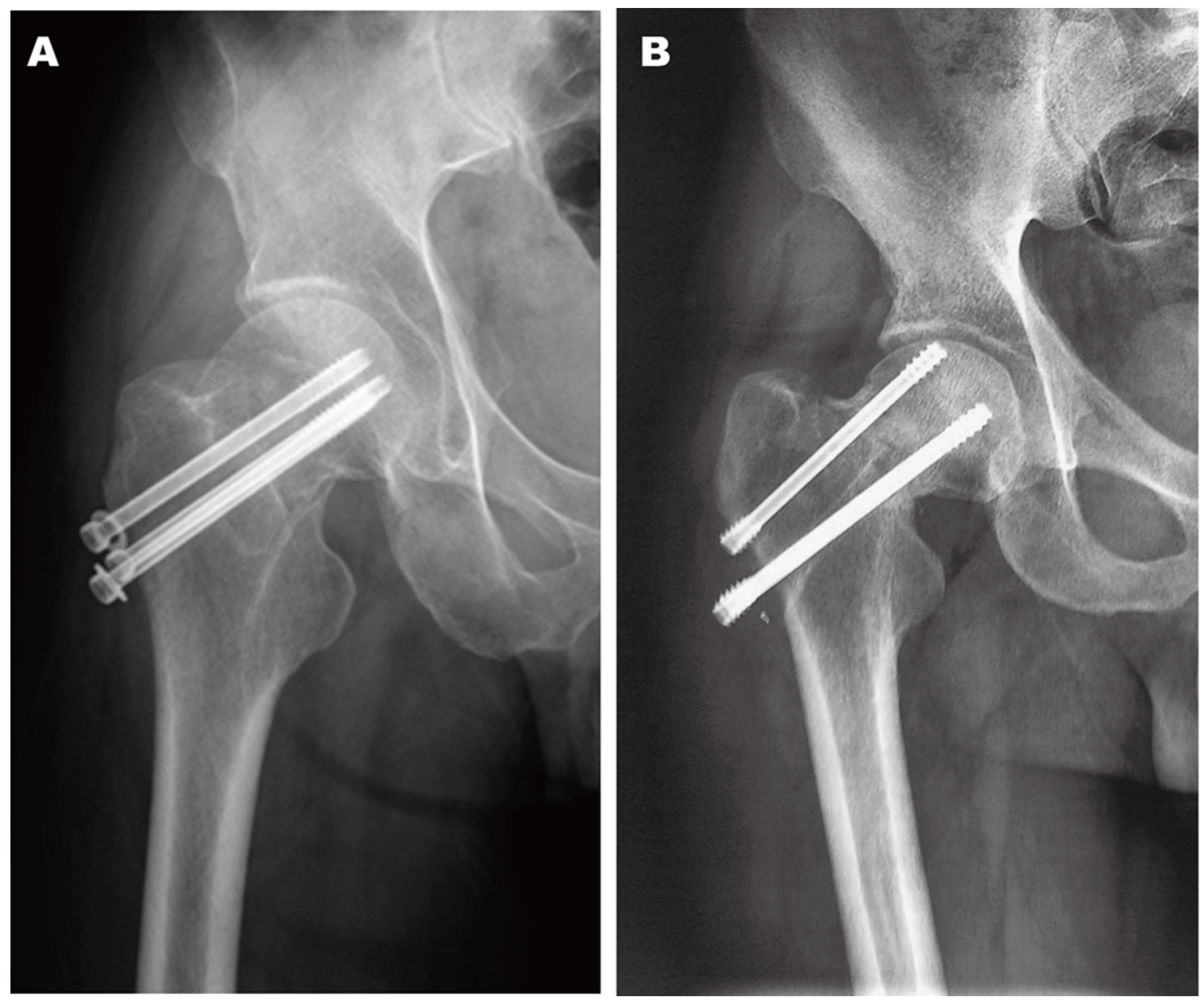

\section{Figure 3}

Typical radiographs with fixation failures. A. Radiographs with screw withdrawal, varus deformity and shortening 12 months after fixation with PTCS. B. Radiographs with screw withdrawal, Varus deformity and shortening 6 months after fixation with DTCS. 

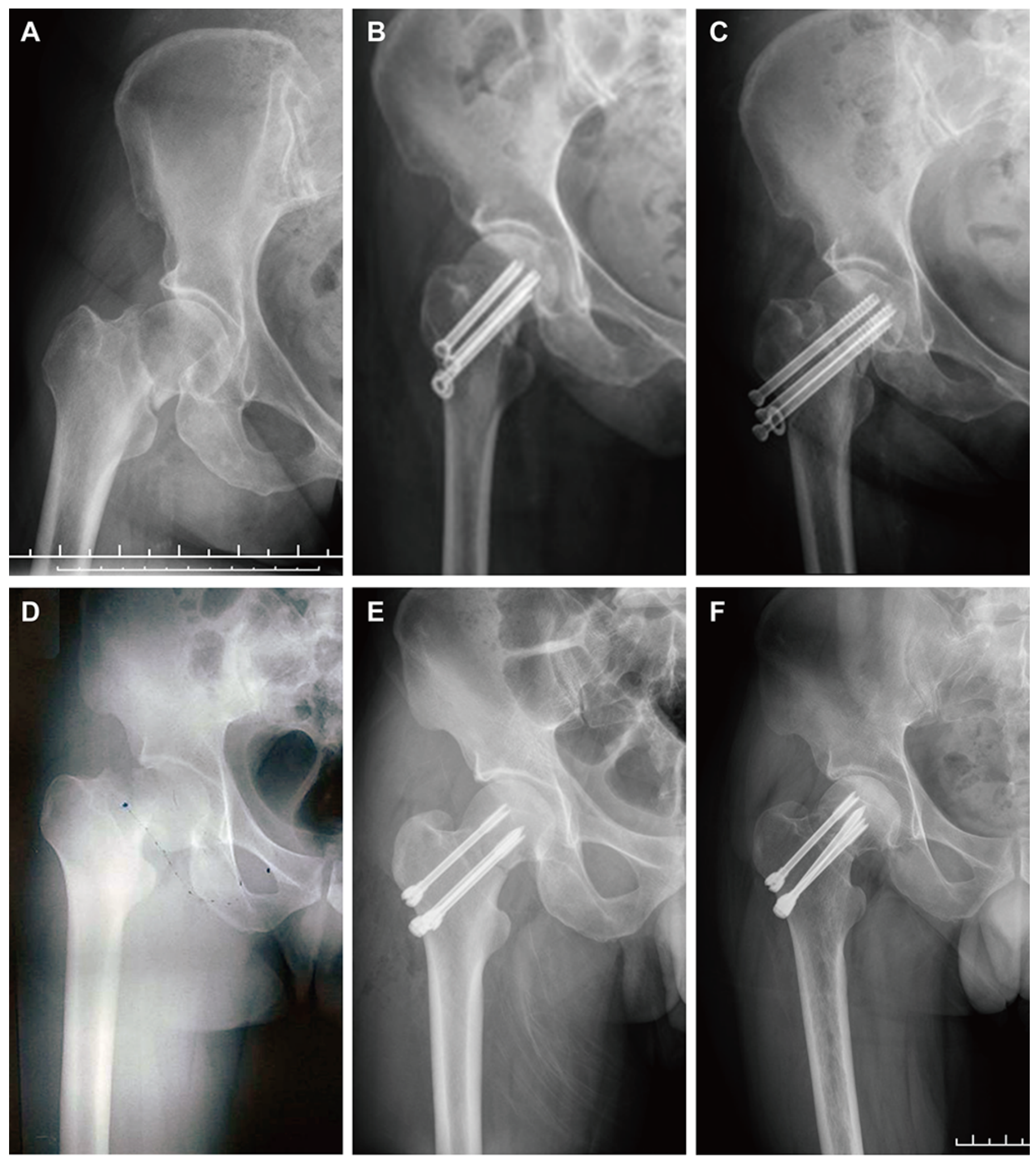

\section{Figure 4}

Typical radiographs with nonunion in PTCS and DTCS group. A-C. Radiographs of injury, post-operation and 9 months after operation in PTCS. D-F. Radiographs of injury, post-operation and 12 months after operation in DTCS. 
A

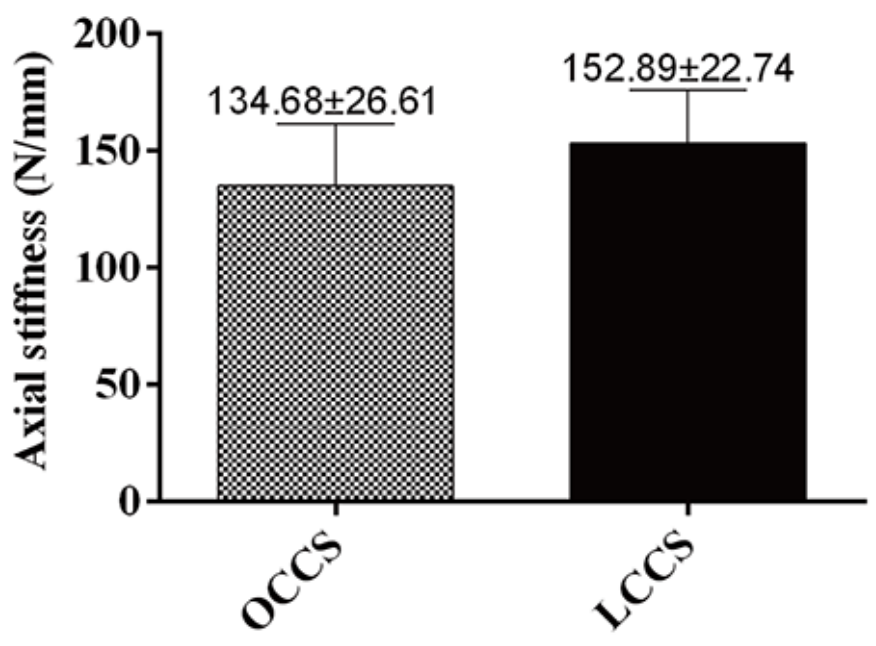

B

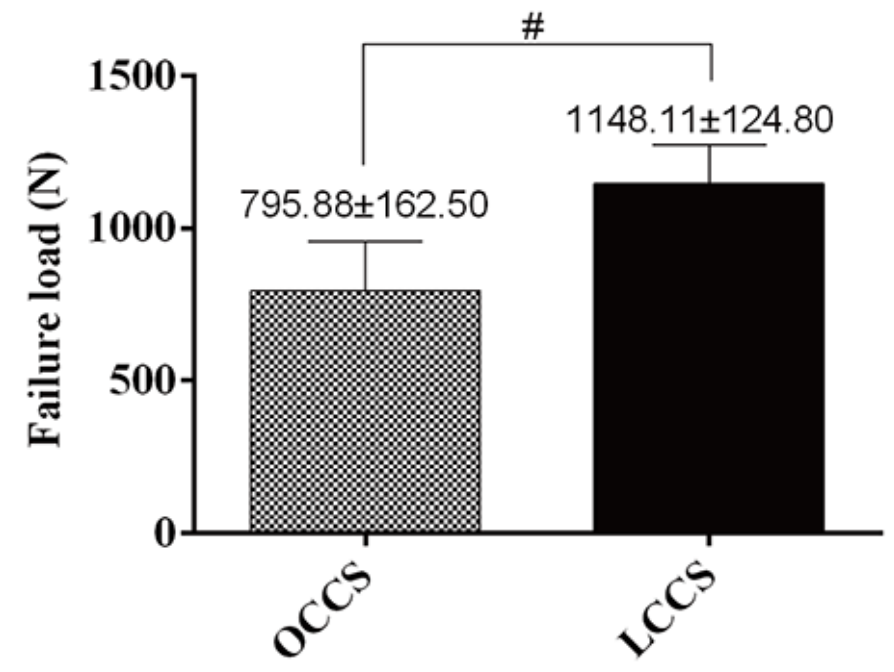

\section{Figure 5}

The axial stiffness and maximum load to failure in PTCS and DTCS group. Data was showed with mean \pm standard deviation, \# significant difference between the two groups ( $\mathrm{p} \otimes 0.05$ ). 